\title{
Corrigendum
}

\section{Corrigendum to "Simulation and Analysis of Uncooled Microbolometer for Serial Readout Architecture"}

\author{
Musaed Alhussein $(\mathbb{C}$ and Syed Irtaza Haider $(\mathbb{C})$ \\ Computer Engineering Department, College of Computer and Information Sciences, King Saud University, Riyadh 11451, Saudi Arabia \\ Correspondence should be addressed to Syed Irtaza Haider; sirtaza@ksu.edu.sa
}

Received 16 August 2017; Accepted 7 September 2017; Published 25 June 2018

Copyright (C) 2018 Musaed Alhussein and Syed Irtaza Haider. This is an open access article distributed under the Creative Commons Attribution License, which permits unrestricted use, distribution, and reproduction in any medium, provided the original work is properly cited.

In the article titled "Simulation and Analysis of Uncooled Microbolometer for Serial Readout Architecture" [1], there was an error in Section 2.3, where the statement "Table 1 shows the thermal parameters of the microbolometer that were used for the simulation [4]" should cite reference [5] in the article instead of reference [4]; the correct statement is as follows: Table 1 shows the thermal parameters of the microbolometer that were used for the simulation [5].

Also, in Results, there was an error in the legend of Figure 8 , where Table 5 should be cited instead of Table 3 ; the correct legend is as follows: "Figure 8: (a) Input thermal image, (b) output for the test cases mentioned in Table 5, case I, (c) case II, (d) case III, (e) case IV, (f) case V, (g) output for $I_{\text {BIAS }}=$ $20 \mu \mathrm{A}, T_{\text {BIAS }}=250 \mu$ s using column-wise readout, and (h) output for case IV mentioned in Table 5 using pair-wise serial readout."

The aforementioned errors do not affect any of the results or conclusions of the published manuscript. The authors apologize for any inconvenience caused.

Moreover, the following statement was missing from the Acknowledgements:

Syed Irtaza Haider would like to thank his M.S. thesis supervisor, Dr. Sohaib Majzoub, and cosupervisor, Professor Muhammad Alturaigi, for their contributions to this work. Some parts of this work were taken from the Master's thesis of Syed Irtaza Haider.

\section{References}

[1] M. Alhussein and S. I. Haider, "Simulation and analysis of uncooled microbolometer for serial readout architecture," Journal of Sensors, vol. 2016, Article ID 9751056, 13 pages, 2016. 


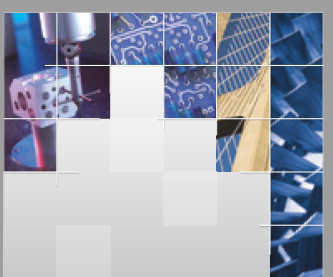

\section{Enfincering}
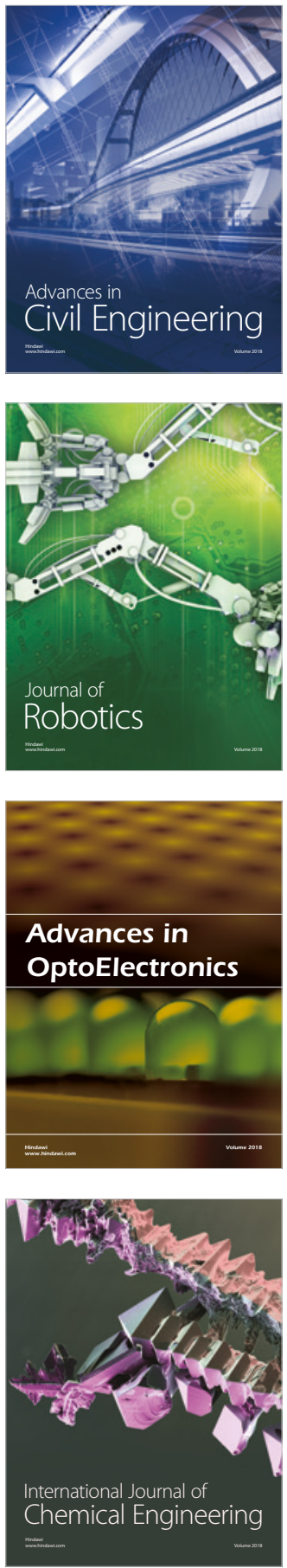

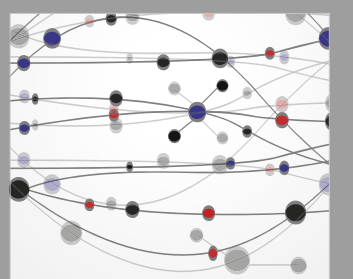

\section{Rotating \\ Machinery}

The Scientific World Journal

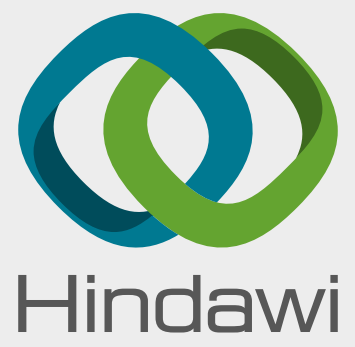

Submit your manuscripts at

www.hindawi.com
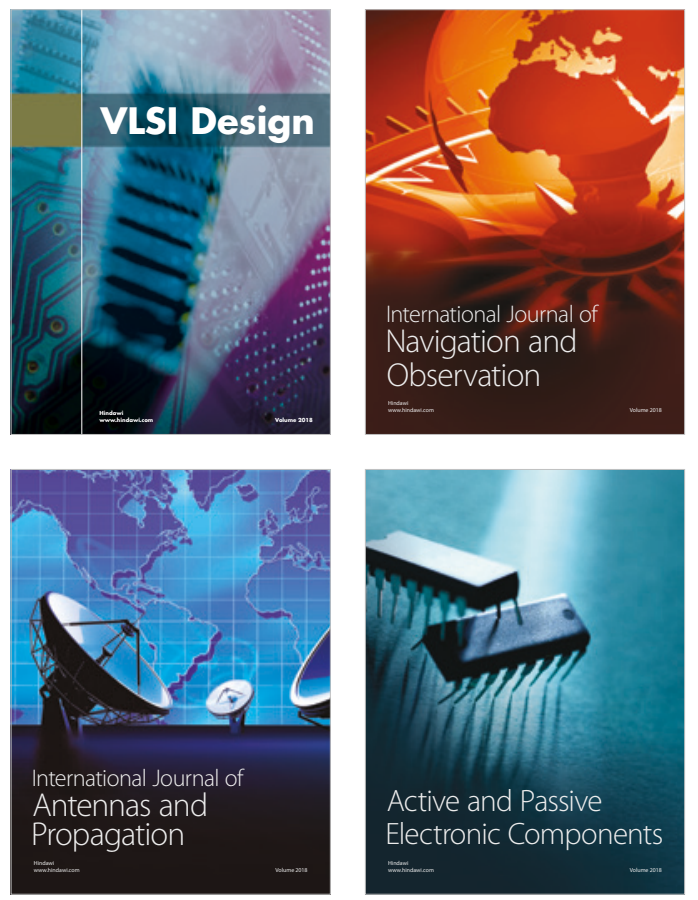
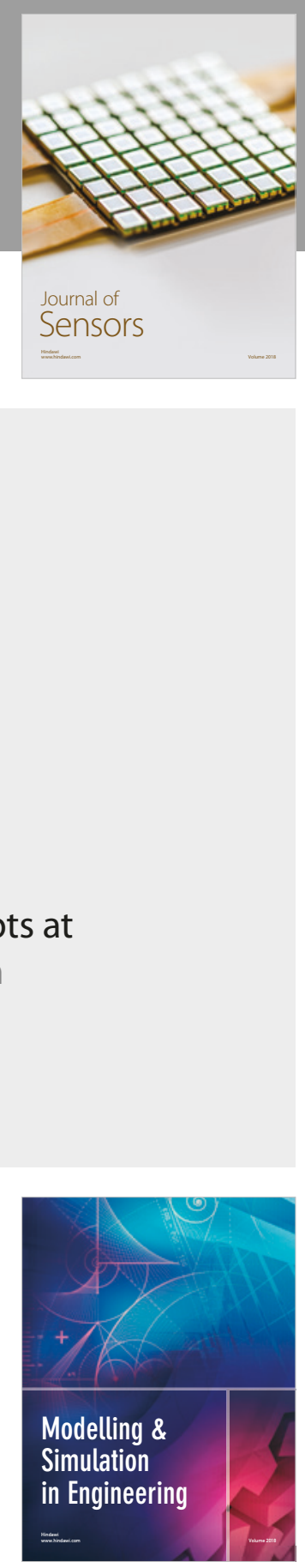

\section{Advances \\ Multimedia}
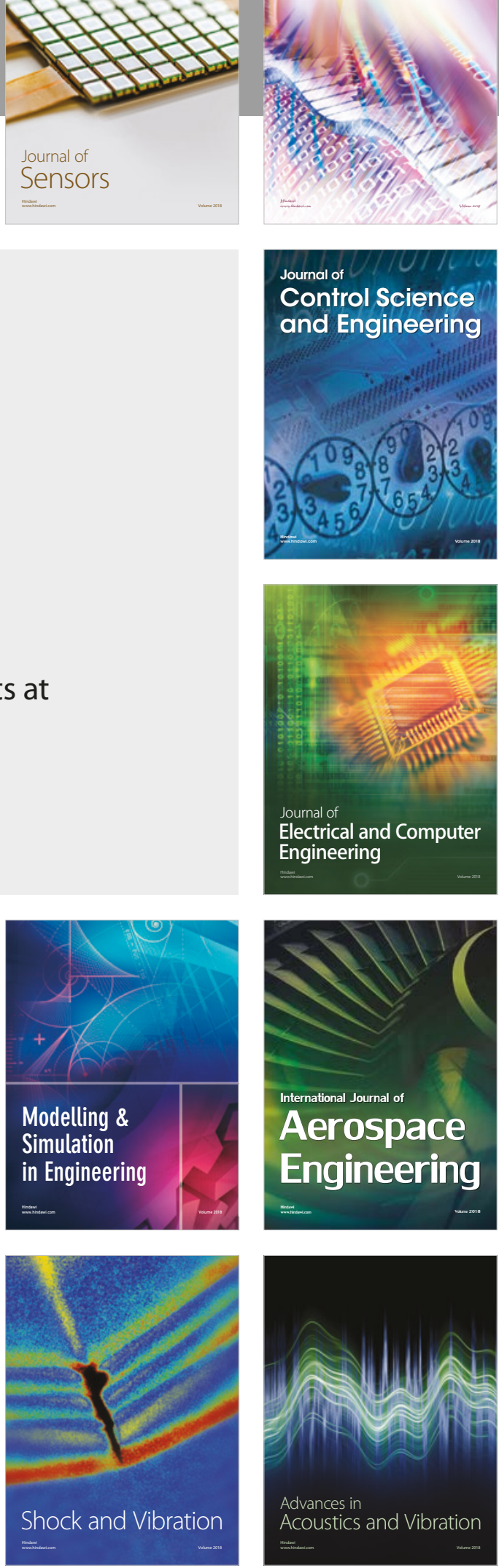